\title{
Association of caregiver demographic variables with neuropsychiatric symptoms in Alzheimer's disease patients for distress on the Neuropsychiatric Inventory (NPI)
}

\author{
Cláudia Godinho ${ }^{1,2}$, Analuiza Camozzato ${ }^{1}$, Renata Kochhann ${ }^{1}$, Márcia Lorena Fagundes Chaves ${ }^{1,23}$
}

\begin{abstract}
Behavioral symptoms are frequently observed in Alzheimer's disease patients and are associated to higher distress for patients and caregivers, early institutionalization, worst prognosis and increased care. Objectives: The objective of the present study was to evaluate the frequency of neuropsychiatric symptoms in a sample of Alzheimer's disease patients and to analyze association between caregiver demographic characteristics and patient symptoms. Methods: Sixty Alzheimer's disease patients (NINCDS-ADRDA) and their caregivers were consecutively included in the investigation by the Dementia Outpatient clinic of Hospital de Clínicas de Porto Alegre. The Neuropsychiatric Inventory (NPI) was applied to evaluate behavioral symptoms and their impact upon caregivers. Age, sex, educational attainment, relationship to the patient, and time as caregiver were obtained from all caregivers. Results: Apathy was the symptom responsible for the highest distress level, followed by agitation and aggression. A significant correlation between total severity NPI and distress NPI was observed. None of the caregiver demographic data showed association to distress. The most frequent symptoms were apathy and aberrant motor behavior. Patients' relatives also considered apathy as the most severe symptom, followed by depression and agitation. Conclusions: Apathy was the most frequent and severe neuropsychiatric symptom. No relationship between caregiver demographic characteristics and distress was observed.
\end{abstract}

Key words: neuropsychiatric symptoms, Alzheimer's disease, distress, caregiver, Brazil

\begin{abstract}
Associação de variáveis demográficas do cuidador e percepção de sintomas neuropsiquiátricos de pacientes com doença de Alzheimer para desgaste mensurados pelo Inventário Neuropsiquiátrico (INP)

Resumo - Sintomas comportamentais são freqüentemente observados nos pacientes com doença de Alzheimer e estão associados a maior desgaste para pacientes e cuidadores, institucionalização precoce, pior prognóstico e mais cuidado. Objetivos: O objetivo do presente estudo foi avaliar freqüência de sintomas neuropsiquiátricos em uma amostra de pacientes com doença de Alzheimer e analisar a associação entre características demográficas do cuidador e sintomas do paciente. Métodos: Um total de 60 pacientes com doença de Alzheimer (NINCDSADRDA) e seus cuidadores foram consecutivamente incluídos na investigação provenientes do Ambulatório de Demência do Hospital de Clínicas de Porto Alegre. O Inventário Neuropsiquiátrico (INP) foi aplicado para avaliar sintomas comportamentais e seu impacto sobre os cuidadores. Idade, sexo, educação, parentesco com o paciente e tempo como cuidador foram obtidos dos cuidadores. Resultados: Apatia foi o sintoma responsável pelo maior nível de desgaste, seguido por agitação e agressão. Uma correlação significativa entre escore total do INP e desgaste foi observada. Nenhuma das variáveis demográficas do cuidador mostrou associação com desgaste. Os sintomas mais freqüentes foram apatia e comportamento motor aberrante. Os familiares do pacientes também consideraram apatia como sintoma mais grave seguido por depressão e agitação. Conclusões: Apatia foi o sintoma neuropsiquiátrico mais freqüente e grave. Nenhuma relação entre as variáveis demográficas do cuidador e desgaste foi observada.
\end{abstract}

Palavras-chave: sintomas neuropsiquiátricos, doença de Alzheimer, desgaste, cuidador, Brasil.

${ }^{1}$ Dementia Clinic, Neurology Service, Hospital de Clínicas de Porto Alegre. ${ }^{2}$ Medical Sciences Post-Graduation Course, UFRGS School of Medicine. ${ }^{3}$ Internal Medicine Department, UFRGS School of Medicine

Márcia Lorena Fagundes Chaves - Rua Ramiro Barcelos, 2350 / sala 2040 - 90035-091 Porto Alegre RS - Brasil - E-mail: mchaves@hcpa.ufrgs.br Received July 17, 2007. Accepted in final form August 28, 2008. 
Behavioral symptoms constitute part of the clinical presentation of Alzheimer's disease (AD) and may occur in any phase of the disease. Some of the most frequent symptoms include agitation, apathy, depression, disinhibition, sleep disturbances, delusions, eating abnormalities, hallucinations, aggression, and personality changes. ${ }^{1}$

The prevalence of the neuropsychiatric symptoms in $\mathrm{AD}$ ranges from $25 \%$ to $80 \%$ where this variation depends on the study methodology. ${ }^{2-7}$ The most common symptom has proved to be apathy, affecting $72 \%$ of patients interviewed using the Neuropsychiatric Inventory (NPI) ${ }^{3-7}$

Neuropsychiatric symptoms in AD are associated with significant distress for patients and caregivers, higher costs and poor prognosis., ${ }^{2,8-10}$ These symptoms are also responsible for the early institutionalization of patients. ${ }^{11}$

Pharmacological and behavioral treatment of non-cognitive symptoms of $\mathrm{AD}$ has been the target of extensive scientific investigation. ${ }^{1,12}$ Reliable and valid tools to measure such symptoms are necessary to allow proper assessment in clinical trials and for the appropriate approach to be adopted in clinical practice.

The Neuropsychiatric Inventory was developed and validated by Cummings (1994) $)^{13}$ with the objective of gathering information on the presence, frequency, and severity of behavioral symptoms in dementia patients. The other goal of this tool is to evaluate the impact of each symptom domain on caregivers. ${ }^{14} \mathrm{NPI}$ encompasses twelve domains (apathy, delusions, hallucinations, agitation/aggression, depression/dysphoria, anxiety, elation/euphoria, aberrant motor behavior, night-time behavior, irritability/lability, disinhibition, and appetite/eating abnormalities). Validated versions of NPI are available in several languages including Greek, ${ }^{15}$ the Yoruba dialect in Nigeria, ${ }^{16}$ Danish, ${ }^{17}$ Japanese, ${ }^{18}$ Korean, ${ }^{19}$ Spanish, ${ }^{20}$ Chinese, ${ }^{21}$ and Brazilian Portuguese..$^{22} \mathrm{~A}$ Brazilian study has shown good reliability and internal consistency of NPI, along with a similar profile of behaviors to those observed in other countries. ${ }^{22}$

The distress NPI (NPI-D) was developed to measure emotional and psychological burden on caregivers under each NPI symptom domain. Besides information on the presence, frequency, and severity of behavioral symptoms, caregivers also score the distress induced by symptoms. A 6point scale is used for the scoring, encompassing the following scores: 0 , not at all distressing; 1 , minimally distressing; 2 , mildly distressing; 3 , moderately distressing; 4 , severely distressing; and 5 , very severely or extremely distressing. ${ }^{14}$ Validity of the NPI-D was assessed by comparing it to the Relatives' Stress Scale (RSS), where significant correlation, adequate test-retest and interrater reliability were observed. ${ }^{4}$

The main hypothesis of this investigation was that some caregiver demographic characteristics would influ- ence perception of distress whereby women, less educated persons, children of patients were expected to experience higher levels of distress. The objective of the present study was to evaluate frequency of neuropsychiatric symptoms in a sample of Alzheimer's disease patients and to analyze association between caregiver demographic characteristics and patient symptoms.

\section{Methods}

Sixty consecutive patients and their caregivers who were seen for a 10-month period in the Dementia outpatient clinic of the Hospital de Clínicas de Porto Alegre and that fulfilled the National Institute of Neurological and Communicative Disorders and Stroke-Alzheimer's Disease and Related Disorders Association (NINCDS-ADRDA) criteria for probable Alzheimer's disease were included in the study. ${ }^{23}$ Patients underwent a full routine evaluation, including: the Mini Mental State Examination, ${ }^{24,25}$ a battery of cognitive tests, the CDR scale, ${ }^{26,27}$ a neurological examination, screening laboratory tests, and a brain CT. After the diagnosis definition, the NPI was applied for the assessment of behavioral symptoms and their impact on caregivers.

Study variables for caregivers were age, sex, educational attainment, level of relationship to the patient, and length of time as caregiver (in months). Demographic and clinical data for patients and caregivers are displayed in Table 1.

According to the sample size calculation, 52 patients and their caregivers would be sufficient for the present study, given a minimum symptom frequency of $46 \%{ }^{28}$ using an alpha error of $5 \%$ and beta error of $20 \%$ determined by the OpenEpi version2 Program.

$\underline{\text { Table 1. Clinical and demographic data of patients and caregivers. }}$

\begin{tabular}{lcc}
\hline Variables & AD patients & Caregivers \\
\hline Gender N (\%) & & \\
$\quad$ Female & $45(75 \%)$ & $50(83 \%)$ \\
$\quad$ Male & $15(25 \%)$ & $10(17 \%)$ \\
CDR N (\%) & $12(24 \%)$ & - \\
1 & $14(29 \%)$ & - \\
2 & $23(47 \%)$ & - \\
3 & & $11(18.3)$ \\
Relationship to the patient & - & $41(68.3)$ \\
Spouse & - & $4(6.7)$ \\
Patient's child & - & $4(6.7)$ \\
Other relative & - & $52.4 \pm 12.8$ \\
Non relative & $77.9 \pm 8.4$ & $9.1 \pm 3.7$ \\
Age * & $4.8 \pm 3.8$ & $48.8 \pm 36$ \\
Years of education * & - & \\
Time as caregiver (months) &
\end{tabular}

${ }^{*}$ mean \pm SD 
Table 2. Association between caregiver distress level and patient symptom domains.

\begin{tabular}{|c|c|c|c|c|}
\hline Symptom domains & Not present & Minimally/mildly & Moderately & Severely/very severely \\
\hline Delusions & $23(54 \%)$ & $4(7 \%)$ & $10(17 \%)$ & $13(22 \%)$ \\
\hline Hallucinations & $36(60 \%)$ & $6(10 \%)$ & $7(12 \%)$ & $11(18 \%)$ \\
\hline Agitation/Aggression & $29(48 \%)$ & $7(12 \%)$ & $9(15 \%)$ & $15(25 \%)$ \\
\hline Depression & $30(50 \%)$ & $10(17 \%)$ & $10(17 \%)$ & $10(17 \%)$ \\
\hline Anxiety & $33(55 \%)$ & $8(13 \%)$ & $6(10 \%)$ & $13(22 \%)$ \\
\hline Euphoria & $56(93 \%)$ & $1(2 \%)$ & $1(2 \%)$ & $2(3 \%)$ \\
\hline Apathy & $23(38 \%)$ & $10(17 \%)$ & $8(13 \%)$ & $19(32 \%)$ \\
\hline Disinhibition & $50(83 \%)$ & $6(10 \%)$ & $3(5 \%)$ & $1(2 \%)$ \\
\hline Irritability/Lability & $41(70 \%)$ & $5(8 \%)$ & $6(10 \%)$ & $7(12 \%)$ \\
\hline Aberrant motor behavior & $37(62 \%)$ & $5(8 \%)$ & $7(12 \%)$ & $11(18 \%)$ \\
\hline Night-time behavior disturbances & $43(72 \%)$ & $2(3 \%)$ & $2(3 \%)$ & $13(22 \%)$ \\
\hline Appetite and eating abnormalities & $42(70 \%)$ & $3(5 \%)$ & $7(12 \%)$ & $8(13 \%)$ \\
\hline
\end{tabular}

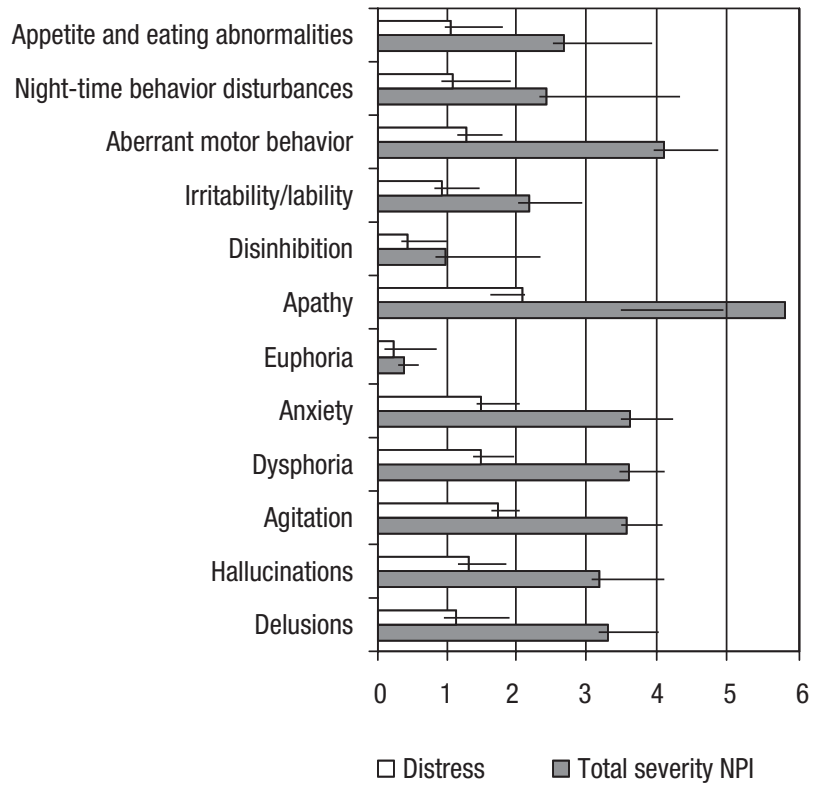

Figure 1. Mean and SD for distress and total severity NPI (frequency $\times$ severity) of each neuropsychiatric symptom.

The study was approved by the Ethics Committee for Medical Research at Hospital de Clínicas de Porto Alegre. Patients and their proxies signed an informed consent before being enrolled onto the study.

\section{Data analysis}

Descriptive statistics (mean, SD and frequency) were calculated for demographic data, symptoms of NPI, and CDR. Spearman's rho correlation coefficients were estimated for age, education, time as caregiver, distress NPI and total severity NPI. The comparison of distress scores between

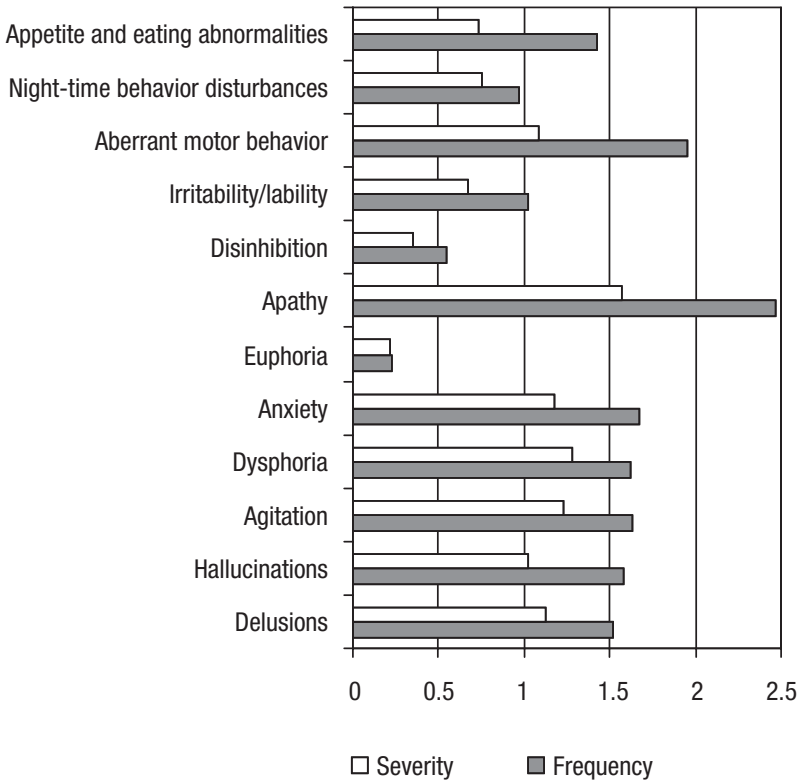

Figure 2. Frequency and severity of symptom domain

the CDR global scores ( $\leq 2$ and 3 ), sex and relationship to the patient was tested with the non-parametric MannWhitney U test. The statistical analysis was performed using the Statistical Package for the Social Sciences (SPSS 14).

\section{Results}

Caregiver distress caused by each neuropsychiatric symptom is presented in Table 2. Apathy caused the highest level of distress followed by agitation and aggression (Figure 1).

Most frequent symptoms were apathy and aberrant motor behavior. Apathy was also considered by caregivers 
Table 3. Correlation of distress NPI with caregiver demographic characteristics and total severity NPI.

\begin{tabular}{lcc}
\hline Variables & $\begin{array}{c}\text { Spearman's Rho } \\
\text { Correlation coefficient }\end{array}$ & P value \\
\hline Age & -0.125 & 0.351 \\
Education & -0.229 & 0.084 \\
Time as caregiver & -0.170 & 0.205 \\
Total severity NPI & 0.731 & 0.000 \\
\hline
\end{tabular}

as the most severe symptom followed by depression and agitation (Figure 2).

No significant correlation between distress and caregiver demographic variables was observed. Only total severity NPI score presented moderate correlation with distress (Table 3). No difference in distress scores was observed between CDR categories $(\mathrm{p}=0.079)$, caregiver sex $(\mathrm{p}=0.976)$ and relationship of the caregiver to the patient ( $\mathrm{p}=0.622$ ) (Mann Whitney $U$ test). No difference in total severity NPI scores was found between CDR categories $(\mathrm{p}=0.681$ ) (Mann Whitney U test).

Correlation between frequency, severity and total severity, and caregiver distress for each symptom domain was significant $(\mathrm{p}<0.001$; moderate to strong) (Table 4$)$.

\section{Discussion}

The present study was developed to evaluate the frequency of neuropsychiatric symptoms in a sample of Alzheimer's disease patients and to analyze association between caregiver demographic variables and distress caused by patient symptoms. The most frequent symptom was apathy as shown in several previous studies. ${ }^{2,15,18,29-32}$

Apathy was also the symptom which caused most distress in caregivers. No association was found between distress and caregiver sex, age and educational attainment, degree of relationship to the patient or time as caregiver. These results showed that distress was independent from the evaluated demographic characteristics. Caregiver distress was strongly associated to neuropsychiatric symptoms because distress was rated in relation to symptoms. The correlation of total severity NPI with the total distress NPI scores has previously been demonstrated to be strong but less homogeneous across the symptoms domains. ${ }^{14} \mathrm{~A}$ recent study on the correlation between caregiver stress and patient clinical characteristics also showed that stress was associated to psychiatric symptoms. ${ }^{33}$ On the other hand, functional impairment degree, severity of cognitive deficit, dementia symptoms, history duration, length of time as caregiver, caregiver living with the patient, and having a previous diagnosis, also correlated with distress. These conflicting findings have been partially linked to cultural differences. However, it is possible that other factors such as study design, concomitant pharmacological treatment or non-pharmacological intervention could also play a part.

Distress NPI did not differ for severity of dementia because total severity NPI was similar across CDR categories. Distress NPI is measured, as outlined above, for each neuropsychiatric symptom. The CDR scale measures cognitive and functional impairment but not neuropsychiatric symptoms. In this sense, severity of dementia by CDR is unable to evaluate distress caused by behavioral symptoms.

As observed earlier, caregivers who are patient relatives presented worst physical and psychological health than pa-

Table 4. NPI Component scores and relationship to NPI-Distress score.

\begin{tabular}{|c|c|c|c|c|c|c|c|}
\hline Symptoms & $\begin{array}{c}\text { Distress } \\
\text { Mean } \pm \text { SD }\end{array}$ & $\begin{array}{l}\text { Frequency } \\
\text { Mean } \pm \text { SD }\end{array}$ & Rho $^{*}$ & $\begin{array}{c}\text { Severity } \\
\text { Mean } \pm \text { SD }\end{array}$ & rho $^{*}$ & $\begin{array}{c}\text { Total severity } \\
\text { Mean } \pm \text { SD }\end{array}$ & rho $^{*}$ \\
\hline Delusions & $1.56 \pm 1.9$ & $1.52 \pm 1.6$ & 0.791 & $1.13 \pm 1.2$ & 0.819 & $3.28 \pm 3.9$ & 0.819 \\
\hline Hallucinations & $1.3 \pm 1.8$ & $1.58 \pm 1.7$ & 0.774 & $1.02 \pm 1.09$ & 0.823 & $3.18 \pm 4.1$ & 0.823 \\
\hline Agitation/Aggression & $1.73 \pm 1.84$ & $1.63 \pm 1.5$ & 0.667 & $1.23 \pm 1.1$ & 0.706 & $3.57 \pm 4.0$ & 0.676 \\
\hline Dysphoria/Depression & $1.47 \pm 1.71$ & $1.62 \pm 1.5$ & 0.719 & $1.28 \pm 1.18$ & 0.792 & $3.58 \pm 4.1$ & 0.780 \\
\hline Anxiety & $1.47 \pm 1.84$ & $1.67 \pm 1.65$ & 0.726 & $1.18 \pm 1.18$ & 0.804 & $3.5 \pm 2.3$ & 0.784 \\
\hline Euphoria/Elation & $0.22 \pm 0.9$ & $0.23 \pm 0.61$ & 0.647 & $0.22 \pm 0.613$ & 0.667 & $0.37 \pm 1.28$ & 0.669 \\
\hline Apathy/Indifference & $2.08 \pm 1.95$ & $2.5 \pm 1.8$ & 0.654 & $1.6 \pm 1.25$ & 0.776 & $5.83 \pm 5.0$ & 0.753 \\
\hline Disinhibition & $0.42 \pm 1.03$ & $0.55 \pm 1.18$ & 0.867 & $0.35 \pm 0.73$ & 0.859 & $0.97 \pm 2.37$ & 0.867 \\
\hline Irritability/Lability & $2.5 \pm 1.4$ & $2.6 \pm 1.0$ & 0.950 & $1.5 \pm 0.7$ & 0.952 & $4.1 \pm 2.8$ & 0.953 \\
\hline Aberrant motor behavior & $1.28 \pm 1.73$ & $1.95 \pm 1.57$ & 0.702 & $0.75 \pm 1.18$ & 0.741 & $4.08 \pm 4.82$ & 0.747 \\
\hline Night-time behavior & $1.08 \pm 1.82$ & $0.97 \pm 1.57$ & 0.913 & $0.75 \pm 1.18$ & 0.954 & $2.42 \pm 4.28$ & 0.939 \\
\hline Appetite/eating abnormalities & $1.05 \pm 1.72$ & $1.43 \pm 1.82$ & 0.760 & $0.73 \pm 1.02$ & 0.798 & $2.67 \pm 3.89$ & 0.788 \\
\hline
\end{tabular}

${ }^{*}$ Spearman rank correlation coefficients (rho) between NPI frequency, severity, total severity scores and NPI-Distress scale score. 
tient relatives who do not perform this role. ${ }^{34-38}$ Since our sample was composed of $94 \%$ of caregiver relatives, this concern is highly relevant. To prevent these health problems the identification of behavioral symptoms and other determinant factors of distress impact, often referred to as 'burden of care', is required.

The study limitations were the small variability of caregiver demographic variables, the inclusion of patients attending an outpatient clinic, which could have prevented the inclusion of more severe cases of dementia, and the fact that the clinic is a reference center for dementia care could have led to a different profile of behavioral symptom frequency and severity compared to those observed in nonspecialized clinics. However, the strength of this study was its stringent selection of AD patients based on contemporary criteria, and the use of good quality caregivers to yield reliable information.

Interventions to reduce caregiver distress should take into account this data in a bid to identify those caregiver and patient characteristics related to higher stress. The finding of apathy as the most frequent symptom causing most distress is an issue for future investigation since this has been demonstrated repeatedly in the literature but has not yet been sufficiently explained.

\section{References}

1. Cummings JL, Fairbanks L, Masterman DL. Strategies for analysing behavioural data in clinical trials involving patients with Alzheimer's disease. Int J Neuropsychopharmcol 1999;2:59-66.

2. Mega MS, Cummings JL, Fiorello T, Gornbein J. The spectrum of behavioral changes in Alzheimer's disease. Neurology 1996;46:130-135.

3. Lyketsos CG, Steinberg M, Tschanz JT, Norton MC, Steffens DC, Breitner JC. Mental and behavioral disturbances in dementia: findings from the Cache County study on memory in aging. Am J Psychiatry 2000;157:708-714.

4. Burns A, Jacoby R, Levy R. Psychiatric phenomena in Alzheimer's disease. I: disorders of thought content. Br J Psychiatry 1990;157:72-74.

5. Burns A, Jacoby R, Levy R. Psychiatric phenomena in Alzheimer's disease. II: disorders of perception. Br J Psychiatry 1990;157:76-4.

6. Burns A, Jacoby R, Levy R. Psychiatric phenomena in Alzheimer's disease. III: disorders of mood. Br J Psychiatry 1990;157:81-84.

7. Burns A, Jacoby R, Levy R. Psychiatric phenomena in Alzheimer's disease. IV: disorders of behaviour. Br J Psychiatry 1990;157:86-94.

8. Lyketsos CG, Sheppard JM, Steinberg M et al. Neuropsychiatric disturbance in Alzheimer's disease clusters into three groups: the Cache County study. Int J Geriatr Psychiatry 2001;16:1043-1053.

9. Lyketsos CG, Lopez O, Jones B, Fitzpatrick AL, Breitner J, DeKosky S. Prevalence of neuropsychiatric symptoms in dementia and mild cognitive impairment: results from the Cardiovascular Health Study. JAMA 2002;288:1475-1483.

10. McKeith I, Cummings J. Behavioural changes and psychological symptoms in dementia disorders. Lancet Neurology 2005;4:735-742.

11. Steele C, Rovner B, Chase GA, Folstein M. Psychiatric symptoms and nursing home placement of patients with Alzheimer's disease. Am J Psychiatry 1990;147:1049-1051.

12. Assal F, Cummings JL. Neuropsychiatric symptoms in the dementias. Curr Opin Neurol 2002;15:445-450.

13. Cummings JL, Mega M, Gray K, Rosenberg-Thompson S, Carusi DA, Gornbein J. The Neuropsychiatric Inventory: comprehensive assessment of psychopathology in dementia. Neurology 1994;44:2308-2314.

14. Kaufer DI, Cummings JL, Christine D et al. Assessing the impact of neuropsychiatric symptoms in Alzheimer's disease: the Neuropsychiatric Inventory Caregiver Distress Scale. J Am Geriatr Soc 1998;46:210-215.

15. Baiyewu O, Smith-Gamble V, Akinbiyi A et al. Behavioral and caregiver reaction of dementia as measured by the neuropsychiatric inventory in Nigerian community residents. Int Psychogeriatr 2003;15:399-409.

16. Kat MG, de Jonghe JF, Aalten P, Kalisvaart CJ, Droes RM, Verhey FR. [Neuropsychiatric symptoms of dementia: psychometric aspects of the Dutch Neuropsychiatric Inventory (NPI)]. Tijdschr Gerontol Geriatr 2002;33:150-155.

17. Hirono N, Mori E, Ikejiri Y et al. [Japanese version of the Neuropsychiatric Inventory--a scoring system for neuropsychiatric disturbance in dementia patients]. No To Shinkei 1997;49:266-271.

18. Choi SH, Na DL, Kwon HM, Yoon SJ, Jeong JH, Ha CK. The Korean version of the neuropsychiatric inventory: a scoring tool for neuropsychiatric disturbance in dementia patients. J Korean Med Sci 2000;15:609-615.

19. Boada M, Cejudo JC, Tarraga L, Lopez OL, Kaufer D. [Neuropsychiatric inventory questionnaire (NPI-Q): Spanish validation of an abridged form of the Neuropsychiatric Inventory (NPI)]. Neurologia 2002;17:317-323.

20. Leung VP, Lam LC, Chiu HF, Cummings JL, Chen QL. Validation study of the Chinese version of the neuropsychiatric inventory (CNPI). Int J Geriatr Psychiatry 2001;16:789-793.

21. Camozzato AL, Kochhann R, Simeoni C et al Reliability of the Brazilian Portuguese version of the Neuropsychiatric Inventory (NPI) for patients with Alzheimer's disease and their caregivers Int Psychogeriatr 2008;20:383-393.

22. McKhann G, Drachman D, Folstein M, Katzman R, Price D, Stadlan EM. Clinical diagnosis of Alzheimer's disease: report 
of the NINCDS-ADRDA Work Group under the auspices of Department of Health and Human Services Task Force on Alzheimer's Disease. Neurology 1984;34:939-944.

23. Folstein MF, Folstein SE, McHugh PR. "Mini-mental state": a practical method for grading the cognitive state of patients for the clinician. J Psychiatr Res 1975;12:189-98.

24. Chaves ML, Izquierdo I. Differential diagnosis between dementia and depression: a study of efficiency increment. Acta Neurol Scand 1992;85:378-382.

25. Hughes CP, Berg L, Danziger WL, Coben LA, Martin RL. A new clinical scale for the staging of dementia. Br J Psychiatry 1982;140:566-572.

26. Chaves ML, Camozzato AL, Godinho C, et al. Validity of the Clinical Dementia Rating scale for the detection and staging of dementia in Brazilian patients. Alzheimer Dis Assoc Disord 2007;21:210-217.

27. Binetti G, Mega MS, Magni E, et al. Behavioral disorders in Alzheimer disease: a transcultural perspective. Arch Neurol 1998;55:539-544.

28. Pang FC, Chow TW, Cummings JL, Leung VPY, Chiu HFK. et al. Effect of neuropsychiatric symptoms of Alzheimer's disease on Chinese and American caregivers. Int J Geriatr Psychiatry 2002;17:29-34.

29. Vilalta-Franch J, Lozano-Gallego M, Hernandez-Ferrandiz M, Llinas-Regla J, Lopez-Pousa S, Lopez OL. The Neuropsychiatric Inventory: psychometric properties of its adaptation into Spanish. Rev Neurol 1999;29:15-19.

30. Fuh JL, Liu CK, Mega MS, Wang SJ, Cummings JL. Behavioral disorders and caregivers' reaction in Taiwanese patients with Alzheimer's disease. Int Psychogeriatr 2001;13:121-128.

31. Politis AM, Mayer LS, Passa M, Maillis A, Lyketsos CG. Validity and reliability of the newly translated Hellenic Neuropsychiatric Inventory (H-NPI) applied to Greek outpatients with Alzheimer's disease: a study of disturbing behaviors among referrals to a memory clinic. Int J Geriatr Psychiatry 2004;19:203-208.

32. Vega UM, Marinho V, Engelhardt E, Laks J. [Neuropsychiatric symptoms in dementias: preliminary report of a prospective outpatient evaluation in Brazil]. Arq Neuropsiquiatr 2007;65:498-502

33. Cassis, Stella Velasques Anderaos et al. Correlação entre o estresse do cuidador e as características clínicas do paciente portador de demência. Rev Assoc Med Bras 2007;53:497-501.

34. Haley WE, Levine EG, Brown SL, Batolucci AA. Stress, appraisal, coping and social support as predictors of adaptional outcome among dementia caregivers. Psychol Aging 1987;2:323-330.

35. Gallagher D, Rose J, Rivera P, et al. Prevalence of depression in family caregivers. Gerontologist 1989;29:449-456.

36. Schulz R, Visintainer P, Williamson GM. Psychiatric and physical morbidity effects of caregiving. J Gerontol 1990;45:181-191.

37. Baumgarten M, Battista RN, Infante-Rivard C, et al. The psychological and physical health of family members caring for an elderly person with dementia. J Clin Epidemiol 1992;45:61-70.

38. Russo J, Vitaliano PP, Brewer DD, et al. Psychiatric disorders in spouse caregivers of care recipients with Alzheimer's disease and matched controls: a diathesis-stress model of psychopathology. J Abnorm Psychol 1995;104:197-204. 